\title{
ARTICULAÇÕES ENTRE EDUCAÇÃO DO CAMPO E ENSINO DE CIÊNCIAS E MATEMÁTICA PRESENTES NA LITERATURA: UM PANORAMA INICIAL
}

\author{
Karine Raquiel Halmenschlager* \\ Juliano Camillo** \\ Carolina do Santos Fernandes*** \\ Graziela Del Mônaco**** \\ Elizandro Maurício Brick ****
}

RESUMO: O presente trabalho tem como objetivo traçar um panorama do modo pelo qual elementos presentes no âmbito da pesquisa e ensino de ciências e matemática dialogam com aspectos emergentes da Educação do Campo. Metodologicamente realizou-se uma revisão de literatura em atas de eventos e periódicos nacionais. Identificou-se, inicialmente, a natureza dos artigos e o nível de ensino abrangido por eles. A análise dos estudos selecionados foi orientada pelos seguintes focos: Relação com a Escola; Pressupostos teórico-metodológicos; Relação com o contexto; Relação com a conceituação científica. Sinaliza-se, assim, a diversidade de perspectivas teóricas e metodológicas em discussão, o que implica também em diferentes maneiras de entender o papel da escola, as relações com o contexto do campo e o papel da conceituação científica. Palavras-chave: Educação do Campo. Ensino de Ciências. Ensino de Matemática.

\section{ARTICULACIONESENTRE LA EDUCACIÓN DEL CAMPOY LA ENSEÑANZA DE CIENCIAS Y MATEMÁTICAS PRESENTES EN LA LITERATURA: UN PANORAMA INICIAL}

RESUMEN: El presente trabajo tiene el objetivo de trazar un panorama del modo por lo cual los elementos presentes en el ámbito de la investigación y enseñanza de ciencias y matemáticas dialogan con aspectos emergentes de la Educación del Campo. Metodológicamente, se realizó una revisión de la literatura en actas de eventos y periódicos nacionales. Se identificaron, inicialmente, la naturaleza de los artículos y el nivel de enseñanza comprendido por ellos. Él análisis de los estudios seleccionados fue orientado por los siguientes focos: Relación con la Escuela; Presupuestos teóricometodológicos; Relación con el contexto; Relación con la conceptuación científica. Se señala, así, la diversidad de perspectivas teóricas y metodológicas en discusión, lo que comprende también diferentes modos de entender el papel de la escuela, las relaciones con el contexto del campo y el papel de la conceptuación científica.

Palabras clave: Educación del Campo. Enseñanza de Ciencias. Enseñanza de Matemáticas.

* Doutora em Educação Científica e Tecnológica pela Universidade Federal de Santa Catarina (UFSC), professora do Departamento de Metodologia de Ensino (MEN) e do Programa de Pós-Graduação em Educação Científica e Tecnológica da Universidade Federal de Santa Catarina (PPGECT). Florianópolis, SC - Brasil. Email: < karine.h@ufsc.br >

* *Doutor em Ensino de Ciências pelo Programa de Pós-Graduação Interunidades em Ensino de Ciências da Universidade de São Paulo (USP), professor do Departamento de Metodologia de Ensino (MEN) e do Programa de Pós-Graduação em Educação Científica e Tecnológica da Universidade Federal

de Santa Catarina (PPGECT). Florianópolis, SC - Brasil. Email:<julianocamillo@gmail.com>.

* * *Doutora em Educação Científica e Tecnológica pela Universidade Federal de Santa Catarina (UFSC), professora do Departamento

de Metodologia de Ensino (MEN) e do Programa de Pós-Graduação em Educação Científica e Tecnológica da Universidade Federal de Santa Catarina (PPGECT). Florianópolis, SC - Brasil. Email:<carolferquimic@hotmail.com>

* * * Doutora em Educação pelo Programa de Pós Graduação em Educação da Universidade Federal de São Carlos (UFSCar), professora do Departamento de Educação do Campo (EDC) da Universidade Federal de Santa Catarina (UFSC). Florianópolis, SC - Brasil. Email:<gdelmonaco@gmail.com>

***** Doutor em Educação Científica e Tecnológica pela Universidade Federal de Santa Catarina (UFSC), professor 
ARTICULATIONS BETWEEN COUNTRYSIDE EDUCATION AND SCIENCE AND MATHEMATICS TEACHING PRESENT IN THE LITERATURE: AN INITIAL PANORAMA

ABSTRACT: This paper aims to provide an overview of how aspects related to "Educação do Campo" [Education for and by the countryside] have been explored in the literature, particularly in Science and Mathematics Teaching. A literature review was carried out in event records and Brazilian journals. First, it was identified the nature of the paper and the educational level they were dealing with. Then, the analysis of selected studies was centered on the following focuses: Relationship with school; Theoretical and methodological assumptions; Relationship with context; Relationship with the scientific knowledge. From that, it is pointed out the diversity of theoretical and methodological perspectives in discussion, which also involves different ways of understanding the role of the school, the relationship with the countryside context and the role of scientific conceptualization.

Keywords: Countryside Education. Science Teaching. Mathematics Teaching. do Departamento de Metodologia de Ensino (MEN) da Universidade Federal de Santa Catarina. Florianópolis, SC - Brasil. Email:<elizandromb@gmail.com.> 


\section{INTRODUÇÃO}

Nos últimos anos, os movimentos sociais campesinos e sindicais relacionados com questões do campo têm-se organizado em torno da luta pela garantia de seus direitos, como direito à terra e, em particular, à educação. São movimentos que se destacam pelo protagonismo dos trabalhadores do campo que nunca antes haviam ocupado a cena educacional brasileira (MOLINA, FREITAS, 2011), reivindicando uma Educação do Campo ${ }^{1}$, pensada desde o modo de vida camponês, e que, para além de uma pedagogia em um sentido restrito, constitui-se de uma visão de desenvolvimento, sociedade e transformação social.

A Educação do Campo, segundo Caldart (2012, p. 259), é um conceito em construção e que "nomeia um fenômeno da realidade brasileira atual, protagonizado pelos trabalhadores do campo e suas organizações", que nas últimas duas décadas têm visado elaborar uma discussão e propor formas de fazer acontecer a escola no contexto camponês. Por originar-se no processo de luta dos movimentos sociais camponeses, traz de forma clara sua intencionalidade maior de construção de uma sociedade sem desigualdades em busca de justiça social (MOLINA, FREITAS, 2011).

As reivindicações dos movimentos sociais colocam em xeque o processo de desvalorização da vida no campo, que parte do pressuposto do campo como um espaço de atraso em relação à cidade, como um lugar de transição ou subordinado às necessidades dos grandes centros e cujos saberes e cultura não possuem relevância. No processo educacional, tal lógica manifesta-se nas tentativas de adaptação dos princípios educacionais das cidades às escolas do campo, proporcionando uma educação generalista e que desconsidera as especificidades deste local, quando não se resume ao simples transporte dos alunos do campo para escolas das regiões urbanas mais próximas.

É importante destacar que, nesta história de lutas, algumas conquistas foram alcançadas, como a Educação do Campo assumir o status de uma política de estado, deixando de ser uma política de governo transitória. Há, no entanto, muito ainda a ser conquistado de modo que se consiga uma Educação efetivamente do Campo, que seja promotora de emancipação daqueles que têm no campo a construção e reprodução da sua vida.

Por meio destas lutas, os trabalhadores visam garantir o direito à escolarização e ao conhecimento como uma de suas estratégias de resistência, construídas na perspectiva de manter seus territórios de vida, trabalho e identidade. Historicamente, os povos camponeses demarcaram lutas que visam, por exemplo, o direito à Terra; condições de trabalho dignas e legítimas e a educação. No interior de diferentes problemáticas vivenciadas pelos camponeses, torna-se fundamental compreender o papel central desempenhado pelo trabalho como princípio educativo, na perspectiva de promoção da autonomia dos indivíduos do campo, entendendo o processo concreto de produção e reprodução material da vida destes sujeitos, inserida na constante luta pela manutenção de sua identidade e do seu espaço. É neste sentido que a escola passa a ser uma escola "do" e "no" campo, não "para" o campo ou simplesmente "no" campo. Mas uma educação que se efetiva pelos próprios membros deste movimento e se funda no reconhecimento e a valorização da identidade destes indivíduos (CALDART, MOLINA, 2004). 
No conjunto de lutas são criados, então, os primeiros Cursos de Licenciatura em Educação do Campo, que começaram a ser implantados em 2006, por meio de projetos piloto desenvolvidos em quatro universidades federais brasileiras ${ }^{2}$, e que atenderam à proposta formulada pelo Ministério da Educação (MEC). Nessa proposta, dentre outros, consta a demanda de que esses cursos sejam ofertados por áreas do conhecimento ${ }^{3}$ como estratégia para enfrentar a lógica disciplinar fragmentária que perpassam as licenciaturas (TAFFAREL et al., 2011).

Em 2015 estavam em funcionamento 42 cursos de licenciatura em Educação do Campo, em diversas instituições de ensino superior (MOLINA, 2015), dos quais grande parte faz formação em Ciências da Natureza e Matemática ${ }^{4}$. Diante disso, tem-se como pressuposto que a existência de diversos cursos de Licenciatura em Educação do Campo com ênfase nas áreas de Ciências da Natureza e Matemática pode estar contribuindo para a promoção de espaços voltados para produção de conhecimentos que, de alguma forma, busquem a articulação entre os princípios e demandas da Educação do Campo (BRASIL, 2010) e discussões presentes no âmbito da pesquisa em Ensino de Ciências e Matemática. Além disso, a Educação do Campo, apesar de um campo relativamente recente, já tem produzido um considerável número de reflexões acerca de práticas desenvolvidas, tanto no ensino superior quanto na educação básica, de maneira que se considera possível identificar quais abordagens teóricas e metodológicas estão sendo utilizadas para se pensar o processo de ensino e aprendizagem em diferentes níveis de ensino.

Deste modo, o objetivo deste trabalho é traçar um panorama do modo pelo qual elementos presentes no âmbito da pesquisa e ensino de ciências e matemática dialogam com aspectos emergentes da Educação do Campo. Na presente pesquisa, foram privilegiados, do ponto de vista analítico, os seguintes aspectos: a relação estabelecida com o espaço escolar; de que forma as questões abordadas nos estudos se relacionam com o contexto do campo; a relação estabelecida com a conceituação científica; e que pressupostos teóricos e metodológicos orientam práticas e discussões. Do ponto de vista descritivo, também se buscou identificar o nível de ensino abrangido pelos trabalhos e a natureza dos estudos selecionados com a revisão.

Com base no exposto, espera-se que as discussões sinalizadas possam contribuir para caracterizar práticas e discussões, de modo a identificar tanto potencialidades para a implementação de um ensino de Ciências da Natureza e Matemática para os sujeitos do campo em sintonia com os princípios da Educação do Campo (BRASIL, 2010), quanto lacunas ainda existentes que carecem de aprofundamento à luz da literatura atual. 


\section{ENCAMINHAMENTOS METODOLÓGICOS}

Realizou-se uma revisão bibliográfica em atas de eventos e em periódicos ${ }^{5}$. No que diz respeito aos eventos, foram considerados: o Seminário Internacional de Educação do Campo (SIFEDOC), específico da Educação do Campo; e o Encontro Nacional de Pesquisa em Ensino de Ciências (ENPEC), pelo fato de concentrar, socializar e divulgar as pesquisas em Educação em Ciências em áreas específicas como a Biologia, a Física e a Química. Em relação aos periódicos, adotou-se, como critério de delimitação, periódicos nacionais classificados como A1 e A2 pelo Qualis CAPES (Comissão de Aperfeiçoamento de Pessoal do Nível Superior) na área de ensino e que possuem publicações acerca do ensino de Ciências e Educação Matemática, quais sejam: Investigações em Ensino de Ciências (IENCI); Ciência \& Educação; Ensaio - Pesquisas em Educação em Ciências; Revista Brasileira de Pesquisa em Educação em Ciências (RBPEC); Boletim de Educação Matemática (BOLEMA). O recorte temporal da revisão foi de 06 anos, de 2009 a 2015. A revisão inicia-se em 2009, ano seguinte à publicação da legislação específica para a Educação do Campo. Foram localizados 30 estudos, assim distribuídos: 
Karine Raquiel Halmenschlager | Juliano Camillo| Carolina do Santos Fernandes Graziela Del Mônaco | Elizandro Maurício Brick

Quadro 1: Estudos localizados a partir da revisão de literatura

\begin{tabular}{|c|}
\hline BOLEMA \\
\hline $\begin{array}{l}\text { MENDES, I. A. O Estudo da Realidade como Eixo da formação Matemática dos professores de } \\
\text { comunidades rurais. Bolema, v. } 23 \text {, n. } 36, \text { p. } 571-595 \text {, ago. } 2012 \text {. }\end{array}$ \\
\hline ENSAIO \\
\hline $\begin{array}{l}\text { CARDOSO, L. R.; ARAÚJO, M. I. O. Currículo de Ciências: professores e escolas do campo. Ensaio, v. } \\
\text { 14, n. 02, p. 121-135, ago-nov. } 2012 .\end{array}$ \\
\hline $\begin{array}{l}\text { PANIAGO, R. N., ROCHA, S. A., PANIAGO, J. N. A pesquisa como possibilidade de ressignificação das } \\
\text { práticas de ensino na escola no/do campo. Ensaio, v. 16, n. 01, p. 171-188, jan-abr } 2014 \text {. }\end{array}$ \\
\hline Investigações em Ensino de Ciências (IENCI). \\
\hline $\begin{array}{l}\text { CREPALDE, R. S., AGUIAR JR, 0. G. A formação de conceitos como ascensão do abstrato ao concreto: } \\
\text { da energia pensada à energia vivida. Investigações em ensino de Ciências, v. 18, n. 02, p. 299-325, } 2013 .\end{array}$ \\
\hline PAULA, H. F., CASTRO, M.E.C. Formulação de questões e mediação da leitura. Investigações em \\
\hline
\end{tabular}

\section{Encontro de Pesquisa em Educação em Ciências (ENPEC).}

CREPALDE, R. S., AGUIAR JR, O. G. O desenvolvimento do conceito energia em um diálogo intercultural entre as ciências e as vivências de estudantes de licenciatura do campo. Atas do VIII Encontro Nacional de Pesquisa em Educação em Ciências (ENPEC). Campinas (SP), 2011.

GONÇALVEZ, F. C., GARCEZ, E.S.C., ARAUJO, P.H.A., ALVES, L. K. T., SOARES, M. H. B., MESQUITA, N. A. S. Planejamento e desenvolvimento de uma disciplina optativa na escola campo: o estágio como espaço de construção de saberes. Atas do VIII Encontro Nacional de Pesquisa em Educação em Ciências (ENPEC). Campinas (SP), 2011.

LIMA, L. A., FREIXO, A. A. Dialogando saberes no campo: um estudo de caso em uma Escola Família Agrícola. Atas do VIII Encontro Nacional de Pesquisa em Educação em Ciências (ENPEC). Campinas (SP), 2011.

MIRANDA, C. T., JUNIOR SANTOS, G. PINHEIROS, N. A. M., SILVEIRA, R. M. C. F. Matemática e CTS: 0 ensino de medidas de áreas sob o enfoque da ciência tecnologia e sociedade em uma escola do campo. Atas do VIII Encontro Nacional de Pesquisa em Educação em Ciências (ENPEC). Campinas (SP), 2011.

SILVA, C.R., FREITAS, D. Ecoletramento. 0 ensino de Ciências na escola do campo. Atas do VIII Encontro Nacional de Pesquisa em Educação em Ciências (ENPEC). Campinas (SP), 2011.

TAVARES, M. L., VALADARES, J. M., CREPALDE, R. S. Uma experiência de articulação entre conhecimentos de uma disciplina de biologia e outra de física do currículo de um curso de licenciatura para o campo com ênfase em ciências da vida e da natureza (CVN) de uma universidade federal brasileira. Atas do VIII Encontro Nacional de Pesquisa em Educação em Ciências (ENPEC). Campinas (SP), 2011.

CREPALDE, R. S., AGUIAR JR., O. G. Palavra própria e palavra alheia: análise de uma Questão Socialmente Controversa numa turma de Licenciatura do Campo. Atas do IX Encontro Nacional de Pesquisa em Educação em Ciências (ENPEC). Águas de Lindóia (SP), 2013.

FERNANDES, C. S., STUANI, G. M. A temática dos Agrotóxicos no Ensino de Ciências: as compreensões de estudantes da Licenciatura em Educação do Campo. Atas do IX Encontro Nacional de Pesquisa em Educação em Ciências (ENPEC). Águas de Lindóia (SP), 2013.

LOPES, T. M., ZANCUL, M. C. S. Concepções de meio ambiente no Projeto Político Pedagógico e nos Planos de Ensino de professores de uma escola do campo. Atas do IX Encontro Nacional de Pesquisa em Educação em Ciências (ENPEC). Águas de Lindóia (SP), 2013.

MUELLER, C. C., LINDNER, E. L. A construção do conhecimento em comunidades rurais e a recuperação dos saberes locais. Atas do IX Encontro Nacional de Pesquisa em Educação em Ciências (ENPEC). Águas de Lindóia (SP), 2013.

SILVEIRA, D. I., LORECINI JÚNIOR, A., FAGUNDES, M. C. V. Educação Ambiental: comparando dados de uma escola urbana com uma escola do campo. Atas do IX Encontro Nacional de Pesquisa em Educação em Ciências (ENPEC). Águas de Lindóia (SP), 2013. 
II Seminário Internacional de Educação do Campo e Fórum Regional do Centro e Sul do RS (SIFEDOC).

BRICK, E. M, BRITTO, N. S. Q. Investigação Temática Freireana no contexto da licenciatura em educação do campo da UFSC: transposiçôes preliminares. Atas do II Seminário Internacional de Educação do Campo e Fórum Regional do Centro e Sul do RS (SIFEDOC). Santa Maria (RS), 2014.

COPELLO, K. R., SANTOS, F. C., MUMBACH, S., MEURER, A. C. Uma atividade diferente em aulas de Matemática na escola do campo. Atas do II Seminário Internacional de Educação do Campo e Fórum Regional do Centro e Sul do RS (SIFEDOC). Santa Maria (RS), 2014.

FERREIRA, D. F. O ensino de Ciências no contexto de comunidades tradicionais na ltha dos Marinheiros: uma análise sobre os saberes de mundo aplicados no ensino de Ciências na Educação de Jovens e Adultos. Atas do II Seminário Internacional de Educação do Campo e Fórum Regional do Centro e Sul do RS (SIFEDOC). Santa Maria (RS), 2014.

LEITE, K. C., PAULA, P. P., FONTANIVE, É. F. Representações sociais na Matemática: um estudo nas escolas do campo. Atas do II Seminário Internacional de Educação do Campo e Fórum Regional do Centro e Sul do RS (SIFEDOC). Santa Maria (RS), 2014.

LOPES FILHO, F. D., BRITO, R. P., LEITE, M. A. O Programa Etnomatemática para o ensino da Matemática no campo: uma reflexão sobre a educação matemática de jovens e adultos na Vila de Tamatateua, Bragança, Pará, Brasil. Atas do II Seminário Internacional de Educação do Campo e Fórum Regional do Centro e Sul do RS (SIFEDOC). Santa Maria (RS), 2014.

PEREIRA, E. L. Metodologia do ensino de Ciências em uma escola do campo em Barracão. Atas do II Seminário Internacional de Educação do Campo e Fórum Regional do Centro e Sul do RS (SIFEDOC). Santa Maria (RS), 2014.

PLENS, D., ADRIANO, J. Contribuições da Escola Paulo Freire para a construção da Educação do Campo. Atas do II Seminário Internacional de Educação do Campo e Fórum Regional do Centro e Sul do RS (SIFEDOC). Santa Maria (RS), 2014.

ROBAINA, J. V., DIAS, L. F., PAZ, F. J. CUNHA, G. G Vivenciando Ciências na Educação do Campo: propostas interdisciplinares para a melhoria da qualidade do ensino em escolas ruraís. Atas do II Seminário Internacional de Educação do Campo e Fórum Regional do Centro e Sul do RS (SIFEDOC). Santa Maria (RS), 2014.

SILVA, A. F., QUEIROZ, J. G. O., SANTOS, M. C., BRICK, E. M. A produção leiteira em passos maia como tema gerador de um projeto comunitário. Atas do II Seminário Internacional de Educação do Campo e Fórum Regional do Centro e Sul do RS (SIFEDOC). Santa Maria (RS), 2014.

SILVA, D. A., MULLER, F. S., DOMARESKA, A. A. Programa Institucional de Bolsas de Iniciação à Docência - PIBID Matemática e a experiência de ensino-aprendizagem no Colégio Estadual Indígena Rio das Cobras. Atas do II Seminário Internacional de Educação do Campo e Fórum Regional do Centro e Sul do RS (SIFEDOC). Santa Maria (RS), 2014.

SILVA, R. F. V. N., LIMA, I. M. S, LIMA, A. S Atividades propostas por professores de Matemática que trabalham em escolas do campo. Atas do II Seminário Internacional de Educação do Campo e Fórum Regional do Centro e Sul do RS (SIFEDOC). Santa Maria (RS), 2014.

SOUZA, M. G. 0 diálogo Freireano como estratégia de pesquisa no Assentamento Renascer. Atas do II Seminário Internacional de Educação do Campo e Fórum Regional do Centro e Sul do RS (SIFEDOC). Santa Maria (RS), 2014.

SPIELMANN, J. W., PACHECO, C. R. C. Os desafios e possibilidades do ensino da Matemática na Educação do Campo: experiências de estágio. Atas do II Seminário Internacional de Educação do Campo e Fórum Regional do Centro e Sul do RS (SIFEDOC). Santa Maria (RS), 2014.

STRAGLIOTTO, M., DUARTE, C. G. As diferentes formas de operar matematicamente no mundo, desenvolvidas e utilizadas por agricultores do estado de Santa Catarina. Atas do II Seminário Internacional de Educação do Campo e Fórum Regional do Centro e Sul do RS (SIFEDOC). Santa Maria (RS), 2014.

A seleção e análise dos estudos foram orientadas pelas seguintes ações:

a) Localização dos trabalhos que apresentam no título, palavras-chave e resumo conjuntamente as seguintes expressões: Educação do Campo, Escolas do Campo, Ensino de Ciências da Natureza e Matemática. 
b) Leitura dos resumos, a partir da qual foram identificados os principais aspectos metodológicos e teóricos orientadores dos trabalhos. Com isso, estabeleceram-se focos de análise, quais sejam:

1. Relação com a Escola: permitindo identificar de que maneira a relação da escola com o trabalho de pesquisa é estabelecida: se a escola configura-se como coparticipante na construção e condução da pesquisa, visando a transformação do espaço escolar, ou seja, se a escola é tomada como um espaço de produção de conhecimento entre alunos-professores-pesquisadores; ou se, por outro lado, a escola é, principalmente, um espaço de tomada de dados e aplicação de resultados das pesquisas, ou seja, como um espaço de reprodução do conhecimento produzido.

2. Pressupostos teórico-metodológicos: visando identificar os fundamentos teóricos e metodológicos das práticas e das discussões no âmbito da educação do campo.

3. Relação com o contexto: buscando identificar qual o compromisso do trabalho de pesquisa com a realidade do campo, ou seja, se as questões do campo são orientadoras da pesquisa; se o campo é o foco da investigação, sem, no entanto, tomar as questões do campo como orientadoras; ou ainda, se o campo é predominantemente ilustrativo. 4. Relação com a conceituação científica: permitindo identificar como os conteúdos científicos são enfocados, ou seja, qual o papel dado ao conceito científico e as relações estabelecidas entre a conceituação científica e questões contextuais do campo.

c) Leitura na íntegra dos estudos selecionados tendo por base os focos de análise anteriormente elencados. Essa leitura também permitiu a identificação da natureza dos artigos e o nível de ensino abrangido nos estudos.

\section{RESULTADOS E DISCUSSÃO}

Os estudos localizados com a revisão de literatura envolveram diversas naturezas. É possível classificá-los segundo os seguintes critérios: (i) Natureza teórica; (ii) Relatos de experiências; (iii) análise de implementação de práticas; (iv) Levantamento e análise de compreensões e v) outros trabalhos empíricos. Os estudos de natureza teórica focaram na discussão acerca dos pressupostos e princípios da Educação do Campo, enfocando, por exemplo, a valorização dos saberes locais e alfabetização científica (MUELLER, LINDNER, 2013); e a relação com os saberes específicos da Matemática, a formação de conceitos (CREPALDE, AGUIAR, 2013b).

Os artigos que trazem relatos de experiência abordam, por exemplo, de que maneira algumas práticas são conduzidas em uma escola do campo, que também atende indígenas, envolvendo ações do Programa Institucional de Bolsa de Iniciação à Docência (PIBID) (SILVA, MULLER, DOMARESKA, 2014). Também foram selecionados relatos de experiências desenvolvidas a partir do levantamento de Temas Geradores como o estudo de Copello et al. (2014), que relata o desenvolvimento de atividades de ensino de matemática em uma escola do campo a partir de um tema gerador; e o trabalho de Plens (2014) que discorre acerca de como a escola insere a história de ocupação de terra pelo Movimento Sem Terra (MST) e relaciona o contexto e as contradições do campo com os conteúdos escolares a partir do Tema Gerador "Energia". Outros estudos se referem a práticas realizadas em componentes curriculares dos cursos de Licenciatura em Educação do Campo das áreas de Ciências da Natureza e Matemática (ROBAINA et al. 2014) e em atividades realizadas no âmbito do estágio docência (BRICK, BRIT'TO, 2014). 
Os trabalhos que se referem à análise e implementação de práticas abarcam tanto uma dimensão mais ampla da atividade educacional, como a reestruturação do currículo (PANIAGO, ROCHA, PANIAGO, 2014), quanto práticas mais pontuais de sala de aula (CREPALDE, AGUIAR, 2013a; PAULA, CASTRO, 2010). A reestruturação curricular caracterizou uma pesquisa-ação, em que o programa escolar esteve pautado em Temas Geradores. As implementações pontuais se deram no âmbito de uma Licenciatura em Educação do Campo e os trabalhos analisam atividades dentro de disciplinas específicas, como atividades de júri simulado (CREPALDE, AGUIAR, 2013a) e mediação de leitura (PAULA, CASTRO, 2010). Gonçalves et al. (2011) abordam a implementação de uma disciplina optativa com foco em atividades experimentais em uma escola do campo, assim como analisam as compreensões de estagiários da licenciatura em Química a respeito do desenvolvimento desta disciplina. Miranda et al. (2011) descrevem e analisam práticas desenvolvidas em uma escola do campo, no contexto da Educação Matemática, acerca de atividades desenvolvidas a partir do tema "Desmatamento da Amazônia". Mendes (2012) discorre sobre um curso de formação continuada realizado no contexto do Curso "Pedagogia da Terra", com foco na Educação Matemática, tendo por base os "Três Momentos Pedagógicos". 6

Alguns estudos tiveram por objetivo realizar o levantamento de compreensões presentes em documentos, com a análise de Projeto Político Pedagógico (PPP) e Planos de Ensino para a identificação de compreensões sobre meio ambiente (LOPES, ZANCUL, 2013). Outros estudos investigaram concepções de estudantes nos diversos níveis de ensino: sobre representações sociais relacionadas à matemática (LEITE, PAULA, FONTANIVE, 2014); acerca da abordagem de temas controversos no ensino de Ciências da Natureza (FERNANDES, STUANI, 2013); envolvendo uma análise crítica de atividades de matemáticas registradas em cadernos de estudantes do campo, do $1^{\circ}$ ciclo do ensino fundamental (SILVA, LIMA, LIMA, 2014). Na mesma direção, há trabalhos que focam no conceito de energia no âmbito da Licenciatura em Educação do Campo, como o estudo de Crepalde e Aguiar (2011) que analisa produções escritas produzidas em uma disciplina em que foram desenvolvidos módulos didáticos relacionados à energia e ambiente. Tavares, Valadares e Crepalde (2011), de forma semelhante, analisam produções de alunos em disciplinas de Biologia e de Física.

Também foram localizados trabalhos que caracterizam pesquisa empírica envolvendo, por exemplo, a comparação entre concepções de alunos do meio urbano e do meio rural, a partir de aspectos relacionados ao consumo de água (SILVEIRA, LORECINI JUNIOR, FAGUNDES, 2013); o estudo sobre a importância do diálogo entre escola e comunidade para enfrentar situações-limite vividas pelas famílias de assentamento rural (SOUZA, 2014); a etnomatemática no contexto das escolas do campo, especificamente na EJA (LOPES FILHO, BRITO, LEITE, 2014) e no contexto da Licenciatura em Educação do Campo (STRAGLIOTTO, DUARTE, 2014). Há trabalhos que desenvolveram pesquisa participante (LIMA, FREIXO, 2011), com foco na identificação de relações entre conhecimentos tradicionais apresentados por estudantes e conhecimentos científicos trabalhados em aulas de Ciências da Escola Família Agrícola. Silva e Freitas (2011) analisam documentos de uma escola de assentamento rural focando na formação ecológica sustentável. Silva et al. (2014) investigavam parâmetros que 
permitem afirmar que o tema "O aumento da produção de leite como principal alternativa para melhorar o sustento na comunidade" caracteriza uma situação significativa para os moradores de Passos Maia/SC. Outro estudo (FEREIRA, 2014) identifica saberes populares de alunos de uma escola do campo e como esses saberes se relacionam com a Ciência.

Dsetaca-se, ainda, que a maior parte dos estudos envolve a educação básica, em especial o Ensino Fundamental. Em termos quantitativos, dos trabalhos analisados, 09 enfocam o ensino fundamental; 05 enfocam o Ensino Médio, 04 enfocam a Educação de Jovens e Adultos. Do total há trabalhos que abordam especificamente a formação de professores do campo, sendo 13 referentes à formação inicial de professores e 01 à formação continuada. Ressalta-se que um mesmo trabalho pode contemplar mais de um nível de ensino.

No que diz respeito aos focos de análise temos os seguintes resultados:

\section{(1) Relação com a escola}

A maioria dos estudos estabeleceu algum nível de relação com a escola básica. Em alguns estudos essa relação ocorreu, principalmente, a partir de atividades em sala de aula, com a divulgação dos resultados da pesquisa (SILVEIRA, LORECINI JUNIOR, FAGUNDES, 2013; LIMA, FREIXO, 2011; FEREIRA, 2014; MIRANDA et al., 2011). Em outros estudos, a intervenção ocorreu em nível de escola, com a oferta de oficinas e/ou disciplinas optativas em escolas do campo (MUELLER, LINDNER, 2013; SILVA, MULLER, DOMARESKA, 2014; GONÇALVES et al., 2011). Outros trabalhos evidenciam uma intervenção mais sistemática no currículo escolar, sendo que os resultados da pesquisa retroalimentaram as práticas curriculares e metodológicas (PANIAGO, ROCHA, PANIAGO, 2014; MENDES, 2010). No entanto, grande parte dos estudos toma a escola como espaço para obtenção de dados e informações de investigação (CARDOSO, ARAUJO, 2012; SILVEIRA, LORECINI JUNIOR, FAGUNDES, 2013; LOPES, ZANCUL, 2013; PEREIRA, 2014; SILVA, LIMA, 2014), ou seja, não explicitam a intencionalidade, a partir da investigação, de transformação do contexto escolar.

Outros trabalhos se referem a planejamentos de atividades a serem realizadas em escolas do campo, planejamentos empreendidos no âmbito dos cursos de Licenciaturas em Educação do Campo, seja como atividades do PIBID (COPELLO et al., 2014); ou projetos de pesquisa a serem realizados a partir da interação entre a universidade, escolas e sujeitos do campo (STRAGLIOTTO, DUARTE, 2014; LOPES FILHO, BRITO; LEITE, 2014); ou de componentes curriculares específicos (ROBAINA et al., 2014). Nesses casos as escolas do campo figuram como o contexto de aplicação de práticas pensadas de antemão, estando ausente nesses trabalhos informações sobre a participação das escolas no planejamento dessas práticas.

Em síntese, os trabalhos apresentam diferentes enfoques com relação ao contexto da pesquisa. Há trabalhos que concebem a escola como contexto de coleta de dados. E neste sentido, a escola do campo possui suas especificidades cotejadas a escolas urbanas. Contudo, há trabalhos cuja concepção de produção de conhecimento pressupõe a transformação dos espaços e sujeitos envolvidos no processo de pesquisa. 


\section{(2) Pressupostos teórico-metodológicos}

Uma característica presente em alguns estudos, como os localizados nas atas do SIFEDOC, que relatam ou analisam práticas realizadas em escolas, é o fato de não explicitarem os referenciais que orientaram as práticas implementadas na escola e/ou em sala de aula.

É possível inferir que as discussões teóricas presentes nos estudos localizados e analisados contemplaram diversos aspectos: (i) construção dos conhecimentos, a partir de Chassot (2001) e Arroyo (2005); (ii) questões de linguagens, com base em Bakhtin (2011); (iii) pressupostos Ciência, Tecnologia e Sociedade (CTS) e Alfabetização Científica, considerando as ideias de Auler e Delizoicov (2001) (iv) princípios da Educação do Campo, com base em Caldart (2004), Arroyo (2004), Fernandes (2004), e na Pedagogia da Alternância e escrita de "caderno realidade"; (v) a agroecologia como matriz científica e tecnológica tendo em vista a gestão camponesa da agrobiodiversidade, com base em Caldart (2013); (vi) etnomatemática, a partir de D’ambrósio (1987; 2001), Wittgenstein (2004) e Foucault (1987; 2000); (vii) educação ambiental, com base em Sauvé (1997, 2005); (vii) Temas Geradores e Abordagem Temática, a partir das ideias de Freire (2005) e Delizoicov, Angotti e Pernambuco (2002); (ix) relação entre conceitos científicos e cotidiano como ascensão do abstrato ao concreto a partir das ideias de formação de conceito em Vigotski (2009) e mediação semiótica em Vigotski (2009) e Bakhtin/Volochinov (2010), (x) alfabetização ecológica, respaldada em Stone e Barlow (2006).

Entre os estudos que relatam ou analisam práticas implementadas destacam-se aqueles que explicitam os pressupostos teóricos e metodológicos relacionados aos Temas Geradores propostos por Freire, na obra "Pedagogia do Oprimido" (FREIRE, 2005). Paniago, Rocha e Paniago (2014), por exemplo, abordam a construção do currículo balizado na ideia de Tema Gerador, identificado a partir da investigação da realidade. Assim como explicitam que as ações estiveram pautadas nos pressupostos de "Educar pela Pesquisa", referenciando, entre outros, Demo (1998). Na mesma direção, Souza (2014) também faz reflexão sobre a investigação de Temas Geradores, para que haja o diálogo entre a realidade vivida pelos assentados e os conteúdos de Ciências e Matemática. Mendes (2012) traz o Tema Gerador como possibilidade para a organização de práticas voltadas para a Educação Matemática, com ênfase na Etnomatemática, a partir dos Três Momentos Pedagógicos.

De modo geral, poucos estudos discutem explicitamente a abordagem de temas como perspectiva teórico-metodológica para a Educação do Campo, mas foi possível identificar, além da ideia de Tema Gerador, distintas formas de inserção de temáticas: (i) a discussão do tema como elemento complementar à discussão teórica previamente estabelecida (CREPALDE, AGUIAR, 2013a, 2013b); (ii), o tema como ilustração dos conceitos científicos abordados em sala de aula (SILVEIRA, LORECINI JUNIOR, FAGUNDES, 2013, ROBAINA et al. 2014; MIRANDA et al., 2011); (iii) o tema como elemento que norteia determinada atividade de formulação de perguntas (PAULA, CASTRO, 2010); (iv) estruturação de práticas pedagógicas que podem remeter a temáticas como o estudo de Crepalde e Aguiar (2011), que explora o conceito de Energia a partir de módulos 
didáticos acerca dos assuntos: "Energia e ambiente"; "Corpo humano e Saúde"; "Energia elétrica, Distribuição e Consumo". (v) A estruturação curricular a partir de eixos formativos que também podem remeter a uma perspectiva temática, como o estudo de Lima e Freixo (2011). Assim, embora haja uma sinalização da abordagem de temas relacionados ao contexto do campo, ainda carece de trabalhos que explicitem mais detalhadamente tais aspectos, de modo a acenar para processos de pesquisa e ensino alicerçados nesta perspectiva educacional.

Especificamente no âmbito da formação inicial de professores em Educação do Campo, diversas perspectivas vêm sendo inseridas nos cursos de graduação. Crepalde e Aguiar (2013b) trazem na discussão teórica realizada elementos da implementação de uma sequência didática numa perspectiva educacional intercultural. Nela situam uma predisposição dos professores em dialogar com as vivências dos estudantes, realizando um movimento de conhecer e reconhecer conhecimentos populares, tradicionais, cotidiano e também da produção científica e tecnológica, sem considerar que os segundos são uma etapa posterior necessária dos primeiros. Buscou-se nessa prática, a partir do uso de narrativas dos estudantes, possibilitar encontros e desencontros entre as vozes dos estudantes e da ciência, de violação da canonicidade (CREPALDE, AGUIAR, 2013b).

Robaina et al. (2014), por sua vez, discutem uma proposta realizada no âmbito de uma disciplina da licenciatura que tomou como pressuposto a aprendizagem significativa, segundo a qual os alunos constroem os próprios saberes a partir de seus conhecimentos anteriores. Não há indicativos, no entanto, de como essa perspectiva se concretizou, uma vez que o relato centra-se nas produções dos alunos, focando nos produtos e não no processo de construção de tais produtos. Outro aspecto a ser destacado nesse trabalho é que a prática relatada teve como objeto promover a aprendizagem sobre diversas metodologias e técnicas de ensino de ciências, reduzindo metodologia à técnica, conforme se depreende das seguintes "metodologias" trabalhadas:

[...] elaboração de mapas conceituais, elaboração de jogos pedagógicos no ensino de ciências, jogos virtuais de ciências, proposição de uma unidade didática de ciências, construção de modelos didáticos, leituras de diferentes textos sobre ensino de ciências, experimentação no ensino de ciências (aulas nos Laboratórios de Química, Física e Biologia) e elaboração de Histórias em Quadrinhos (HQs) (ROBAINA et al., 2014, p. 2031).

Crepalde e Aguiar (2011) se baseiam nas perspectivas vigotskiana e bakhtiniana para discutir as concepções alternativas. Buscam, a partir da fala dos licenciandos, construir um diálogo entre diferentes significados da Educação do Campo relacionados ao conceito de energia, ou seja, há uma preocupação com as ideias iniciais desses sujeitos.

Já Gonçalves et al. (2011) abordam referenciais que discutem o papel dos estágios na formação inicial de professores, seu caráter formativo no que diz respeito ao exercício da docência quanto relacionado ao papel da pesquisa na formação de professores.

O trabalho de Paula e Castro (2010) se refere a uma prática de leitura, compreendida não como letramento científico, mas como parte do processo 
de letramento na língua materna dos estudantes, no sentido de que seja responsabilidade de professores de todas as áreas a formação de bons leitores e produtores de texto. Tal perspectiva sobre leitura é situada como recorrente na área de Educação em Ciências, embora também seja explicitada uma compreensão particular de leitura balizada na concepção de Bakhtin (PAULA, CASTRO, 2010). Segundo os autores, a leitura implica um encontro de no mínimo duas consciências, o horizonte conceitual do leitor e do autor, sendo a leitura e o ato concreto de compreensão não um movimento passivo de receber o discurso de autoridade, mas um movimento ativo, responsivo, implicando complementar, questionar ou negar enunciações. Nesse sentido, foi realizada uma prática de mediação de leitura inspirada em uma pesquisa anterior que propõe um método para aumentar a proficiência de estudantes na leitura de textos didáticos de Física. Tal método foi implementado em três fases, a primeira fase consistiu na leitura e formulação de questões sobre o texto, tais questões seriam classificadas em três categorias com pontuações distintas, são elas: questões cujas respostas se encontram no texto; questões cuja resposta o leitor não conhece ou compreende como parte do texto; e questões ligadas ao conteúdo do texto, mas que o texto não traz respostas. Numa segunda fase um par (colega de turma) avaliou as questões atribuindo pontuação pré-estipulada. Numa terceira fase ocorreu a socialização das experiências.

É possível sinalizar, portanto, que diferentes referenciais teóricos, amplamente discutidos no âmbito da pesquisa em ensino de Ciências e Matemática estão sendo mobilizados para a proposição de práticas que estabelecem algum nível de sintonia com as demandas da Educação do Campo. Destaca-se, em especial, nos estudos analisados, a articulação com Tema Gerador e com a Etnomatemática.

\section{(3) Relação com o contexto}

As relações estabelecidas entre as pesquisas realizadas e o campo se deram, principalmente, de três maneiras. Em alguns estudos o campo é algo constitutivo do objeto de investigação, com o estabelecimento de práticas em sintonia com uma perspectiva educacional voltada para uma melhor compreensão da realidade do campo que parece remeter a um processo de intervenção e transformação. Nesse sentido, há trabalhos que buscam: problematizar a produção de tabaco e outros processos (MUELLER, LINDNER, 2013); promover uma reestruturação curricular a partir de temáticas significativas para a comunidade (PANIAGO, ROCHA, PANIAGO, 2014); investigar contradições da produção leiteira, principal fonte de renda de uma localidade (SILVA et al., 2014); promover o planejamento de um ensino de estatística básica, leitura de tabelas e gráficos a partir de dados de sobre uma localidade (COPELLO et al., 2014); analisar exercícios de matemática em uma perspectiva crítica (SILVA, LIMA e LIMA, 2014). Silva, Lima e Lima (2014), em especial, argumentam que a educação do campo deve enfrentar o desafio de ensinar conteúdos matemáticos relacionados à cultura e diversidade do campo e evidenciam que nos:

[...] cadernos analisados prevalecem atividades matemáticas de Referência à Matemática

Pura, com exercícios do tipo "arme e efetue", "resolva a questão" e outros enunciados 
similares, sem qualquer referência ao contexto social dos camponeses ou de realidades diferentes. (SILVA, LIMA e LIMA, 2014 p. 3730).

Ainda sobre a compreensão do campo como espaço de investigação e transformação, Lima e Freixo (2011) tratam de uma escola familiar agrícola pautada na pedagogia da alternância que tem como foco explícito as relações como o campo no sentido de melhor compreender o espaço em que os estudantes vivem e uma interlocução forte com a comunidade. Os autores explicitam, ao abordarem a estrutura curricular da escola:

[...] um quarto eixo está nos Serões, aqui entendidos como tempo livre ao final do dia quando alunos, monitores e agentes externos (professores convidados, lideranças comunitárias da região, membros de organizações não governamentais, etc.) se encontram para explorar temáticas relevantes à formação dos estudantes, mas que extrapolam o universo disciplinar das matérias lecionadas na escola (LIMA, FREIXO, 2011, p. 06).

Na mesma direção, no estudo de Silva e Freitas (2011) a questão do contexto local do assentamento aparece de forma enfática e é endossada a partir dos conceitos presentes no Projeto Polítco Pedagógico (PPP) da escola, conforme salientado: Identidades culturais; Formação integral; Interação com o meio ambiente; Conscientização ecológica; Desenvolvimento Sustentável; Agricultura familiar; Permanência na terra; Cidadania; Assentamento agrário; Cana de açúcar; Arrendamento; Justiça Social; Reforma Agrária; Movimentos Sociais; Trabalho; Interdisciplinaridade; Ecoletramento (SILVA, FREITAS, 2011, p. 06).

Em outros estudos, o campo é compreendido como contexto constitutivo do objeto de investigação da prática educativa, tendo essa prática o foco em compreender e valorizar os saberes dos camponeses, articulando-os com os conhecimentos científicos. Entretanto, sem uma perspectiva explícita de colocar esses saberes em movimento para transformação da realidade. Nesse sentido, o trabalho de Crepalde e Aguiar (2013b) relatam, a partir do aprofundamento teórico realizado, um exemplo de atividade em que surgiram relações entre a energia pensada e vivida pelos alunos do curso de Licenciatura em Educação do Campo. Paula e Castro (2010), ao realizarem a análise de uma atividade de leitura sobre as 'influências da lua", cuja temática é potencialmente relacionável com a vida cotidiana dos estudantes, apesar de promoverem a atividade considerando a leitura como uma ação responsiva, como um diálogo de consciências, não trazem discussões que remetam para a transformação da realidade. Além disso, Lopes, Brito e Leite (2014), por sua vez, fazem reflexões teóricas a respeito da matemática como ciência e argumentando a favor da necessária articulação entre a matemática escolar com a cultura e os saberes matemáticos dos camponeses. E, na perspectiva da etnomatemática, Stragliotto e Duarte (2014) evidenciam as diferentes formas de lidar com a matemática do homem do campo para contribuir com o currículo escolar de matemática e a melhoria da qualidade dos processos educativos na educação do campo, sem, contudo, discutir possíveis transformações na realidade camponesa.

Por fim, há estudos que colocam o campo não como um objeto direto de estudo da prática educativa, ou seja, trazem o campo como um contexto de aplicação 
do que é ensinado ou aparecendo de modo periférico (SILVEIRA, LORECINI JUNIOR, FAGUNDES, 2013; ROBAINA et al., 2014; CREPALDE, AGUIAR, 2011; MIRANDA, et al., 2011; TAVARES, et al., 2011, SPIELMANN, PACHECO, 2014).

Em linhas gerais, a relação com o contexto apresentou-se de três maneiras conforme supracitado. Nesta direção, defende-se que relações explícitas e orgânica com o contexto, neste caso o campo, são de fundamental importância para um trabalho educacional em uma perspectiva transformadora, considerando os pressupostos da Educação do Campo.

\section{(4) Relação com a conceituação científica}

A análise dos estudos permite explicitar os modos pelos quais a conceituação científica toma lugar nos trabalhos analisados: centralidade na conceituação científica; relação da conceituação científica com questões do campo; conceituação científica que extrapola as questões do campo.

No primeiro caso, em que a conceituação científica aparece como central na organização da atividade educacional, tem-se como exemplo o trabalho de Crepalde e Aguiar (2011), em que as temáticas discutidas na sala de aula derivam do conceito de Energia, ou seja, o conceito científico é o centro organizador das temáticas. A mesma centralidade da conceituação científica aparece em Gonçalves et al. (2011), que abordam o desenvolvimento de atividades experimentais enfocando transformações químicas, densidade, modelos atômicos como aspecto central, de modo que não estabelecem relações com questões do campo. No estudo de Miranda et al. (2011) a ênfase está no conceito de medida de área, o que é feito lançando mão do enfoque CTS.

No segundo caso, em outros estudos a conceituação científica surge articulada com o contexto do campo, tem-se como exemplo os trabalhos de Crepalde e Aguiar (2013b) e Paula e Castro (2010). Tanto Crepalde e Aguiar (2013b) quanto Paula e Castro (2010) estabelecem uma articulação entre os conceitos científicos e os conhecimentos populares, tradicionais sem a preocupação explícita com a compreensão profunda e transformação do contexto concreto do campo. Embora se refiram a conceitos científicos - como o de energia no caso de Crepalde e Aguiar (2013b) - a preocupação explícita não se restringe apenas a ensinar os conceitos científicos, mas estabelecer uma relação respeitosa com o que pensam os alunos. Consideram o contexto concreto dos alunos apenas na medida em que reconhecem que é desse contexto que se originam as suas visões/explicações, também compreendidas como legítimas.

Por fim, no terceiro grupo, estão os trabalhos nos quais se pode evidenciar a preocupação de extrapolar o conteúdo escolar para além da conceituação científica, englobando aspectos sociais, ambientais, culturais, econômicos, envolvendo também a construção de espaços formativos informais, ampliando, inclusive, a prática/concepção de currículo, em uma perspectiva comprometida com a transformação da realidade dos educandos. Neste sentido, o trabalho de Lima e Freixo (2011) apresenta uma argumentação em que a conceituação científica está atrelada à possibilidade de melhor compreender as situações vivenciadas pelos estudantes. Essa articulação está materializada no currículo da 
escola, a partir da inserção de eixos formativos: Escola, Família e Comunidade (definido para o $6^{\circ}$ ano); Sustentabilidade ( $7^{\circ}$ ano); Convivência com o semiárido ( $8^{\circ}$ ano) e Política $\left(9^{\circ}\right.$ ano). Os autores, no entanto, sinalizam certa dificuldade em romper com a lógica curricular seriada:

\begin{abstract}
Esta tarefa tem se mostrado deveras complexa, principalmente no que tange ao Ensino de Ciências, sendo precariamente efetuada na prática da sala de aula, segundo nos informou a direção da escola e a professora de ciências, que relatou sua dificuldade em estabelecer relações entre os conteúdos de ciências, principalmente do $9^{\circ}$ ano, com os eixos formativos, fato que ela acredita estar relacionado à sua falta de domínio dos assuntos a serem abordados nesta série (química e física). As observações das aulas de ciências também dão suporte a esta afirmação, na medida em que foi possível perceber que a professora toma como principal instrumento pedagógico o livro didático de ciências, de forma desarticulada ao contexto dos estudantes e aos eixos formativos definidos para cada série (LIMA, FREIXO, 2011, p. 5).
\end{abstract}

A análise dos trabalhos aqui feita evidencia também que a organização do currículo e de práticas de ensino a partir de Temas Geradores mostra-se como uma alternativa para a inserção de novos elementos aos programas escolares, abarcando, desta forma, questões sociais, culturais, políticas, ambientais e/ou econômicas articuladas com a conceituação científica, a exemplo do que trazem Paniago, Rocha e Paniago (2014) e Mendes (2012).

Paniago, Rocha e Paniago (2014), na perspectiva dos Temas Geradores, defendem a abordagem, na sala de aula, de situações relevantes advindas de uma investigação da realidade e que efetivam a perspectiva da pesquisa como ferramenta pedagógica. No contexto por eles investigado, o tema selecionado relaciona-se com a recuperação de uma nascente que abastece o local e representa um problema socioambiental, que extrapola a conceituação científica particular. Segundo os autores:

\begin{abstract}
Após o estudo inicial, que contou com o saber de várias áreas de conhecimento, foram trabalhadas, a partir de planejamentos coletivos orientados pelas investigadoras, as características do solo, da vegetação do local, a legislação ambiental, as formas de reflorestamento, as mudanças climáticas, a germinação pela quebra de dormência, os tipos de sementes (dura, leve, moles), a função ecológica das espécies, a leitura e a produção de texto, os conceitos de medidas de comprimento, a área de figuras planas, os tipos de ângulos, estatística, porcentagem, problemas, etc. (PANIAGO, ROCHA, PANIAGO, 2014, p. 181).
\end{abstract}

De forma semelhante, Mendes (2012) argumenta em favor da articulação entre saberes específicos da Matemática e situações relevantes da comunidade em que os alunos estão inseridos, a partir do estudo da realidade, reorientando o currículo escolar para o contexto investigado. Nas palavras do autor: "[...] essa forma de produzir conhecimento escolar proporciona a conexão entre os saberes escolares, cotidianos e científicos, como uma rede de significados que conduz o aluno à formulação de novos pensamentos acerca da compreensão do mundo presente [...]" (MENDES, 2012, p. 577).

Ele descreve como o processo de investigação da realidade, de construção do programa escolar e de implementação em sala de aula. As temáticas exploradas 
enfocaram, entre outros aspectos, os processos produtivos e econômicos dos assentamentos, a exemplo na investigação da matemática praticada por comerciantes e agricultores, o que permitiu o estudo de formas geométricas, medições e cálculos, cubação da terra, produção de verduras e comercialização da produção.

\section{CONSIDERAC̣ÕES FINAIS}

Os resultados apresentados neste artigo permitem identificar a diversidade de perspectivas teóricas e metodológicas em discussão nos estudos que abordam a Educação do Campo e o ensino de Ciências e Matemática, o que implica também em diferentes maneiras de compreender as relações com escola, com o contexto do campo e o papel da conceituação científica.

Em relação à escola, compreende-se, neste estudo, a necessária a superação da perspectiva que toma o contexto escolar como mero espaço de obtenção de dados e de reprodução ou aplicação de conhecimentos produzidos fora dali, como evidenciado em alguns estudos.

No que diz respeito às relações estabelecidas com o contexto do campo, as discussões apresentadas mostram a importância de se avançar na proposição de práticas educativas que articulem, de forma mais sistemática e profunda, questões do campo e o ensino de Ciências e Matemática, uma vez que é recorrente a presença de aspectos da vida no campo como simples ilustração das discussões realizadas em sala de aula, nos diferentes níveis de ensino. Como apontado na introdução do presente texto, a Educação do Campo surge da necessidade dos povos do campo de uma educação que se dê a partir deste contexto e, ao mesmo tempo, tenha o compromisso com as transformações na sociedade. Logo, a produção de conhecimento deve estar comprometida com os sujeitos do campo de modo a criar possibilidades efetivas de transformação social.

Em relação à conceituação científica, é possível indicar que há uma predominância, nos estudos analisados, em tomá-la como eixo central do processo educativo, em detrimento da inserção de outros elementos, como aspectos sociais, ambientais, culturais, econômicos, políticos, nas abordagens realizadas e/ou discutidas. Contudo, compreende-se, neste trabalho, que o conteúdo escolar não se limita à conceituação científica de modo restrito e, assim, a abordagem e problematização de situações relevantes para a comunidade escolar, por exemplo, pode contribuir para resignificar os conceitos científicos de modo concreto, não como um fim em si mesmos, propiciando compreensão efetiva das problemáticas vividas e possibilidades mais conscientes de intervenção na realidade, de fornecer instrumentos para que os sujeitos do campo possam melhor compreender e intervir em sua realidade.

A estruturação dos programas escolares a partir de Temas Geradores (FREIRE, 2005), em sintonia com a Abordagem Temática Freireana (DELIZOICOV, ANGOT'TI, PERNAMBUCO, 2002), mostra-se, conforme os estudos de Paniago, Rocha e Paniago (2014), Brick e Britto (2014) e Mendes (2012), como uma alternativa para a superação dos limites anteriormente explicitados. Pressupostos balizadores dessa perspectiva educacional, como a problematização, a dialogicidade, a conscientização e a transformação podem contribuir para se pensar uma Educação do Campo em que o aluno é compreendido como sujeito 
do conhecimento e a realidade da sua comunidade é aspecto constitutivo da programação escolar, respeitando-se a diversidade do campo em seus aspectos sociais, culturais, ambientais, políticos, econômicos, de gênero, geracional e de raça e etnia, de acordo com os princípios da Educação do Campo (BRASIL, 2010). Por isso, torna-se relevante, em pesquisas futuras, lançar um olhar para as possíveis articulações entre a abordagem de temas, em especial a Abordagem Temática Freireana, e a Educação do campo.

\section{REFERÊNCIAS}

ARROYO, M. A educação básica e o movimento social do campo. Brasilia: Articulação Nacional, 2005. ARROYO, M. Por um tratamento público da Educação do Campo. MOLINA, Mônica C; JESUS, Sonia M. A. (org.). Contribuições para a construção de um projeto de Educação do Campo. Brasília, DF: [s.n], 2004.

AULER, D.; DELIZOICOV, D. Alfabetização Científico -Tecnológica para quê? Ensaio, Belo Horizonte, v. 03. n. 1, Jun. 2001.

BAKHTIN (VOLOCHINOV), M. Marxismo e filosofia da linguagem. São Paulo: Hucitec, 2010. BAKHTIN, M. Estética da criação verbal. São Paulo: Martins Fontes, p. 261-306, p. 393-410, 2011. BRASIL. Decreto $\mathbf{n}^{\mathbf{0}} \mathbf{7 . 3 5 2}$, de 4 de novembro de 2010. Dispõe sobre a política de educação do campo e o Programa Nacional de Educação na Reforma Agrária - PRONERA. Brasília: 2010.

BRICK, E. M, BRITTO, N. S. Q. Investigação temática freireana no contexto da licenciatura em educação do campo da UFSC: transposiçôes preliminares. Atas do II Seminário Internacional de Educação do Campo e Fórum Regional do Centro e Sul do RS (SIFEDOC). Santa Maria (RS), 2014.

CALDART, R. Educação do Campo. In: CALDART, R. S.; PEREIRA, I. B.; ALENTEJANO, P.; FRIGOTO, G. Dicionário da educação do campo. São Paulo: Expressão popular, 2012.

CALDART, R. S. A Escola do Campo em Movimento. In: ARROYO, M. G.; CALDART, R. S.; MOLINA, M. (org.). Por uma Educação do Campo. Petrópolis, RJ: Vozes, 2004

CALDART, R. S. Desafios do vínculo entre trabalho e educação na luta e construção da Reforma Agrária Popular. Texto apresentado como trabalho encomendado na $36^{\text {a }}$ Reunião anual da Anped, GT Trabalho e Educação. Goiânia, 30 setembro 2013.

CARDOSO, L. R.; ARAÚJO, M. I. O. Currículo de ciências: professores e escolas do campo. Ensaio, v. 14, n. 02, p. 121-135, ago-nov. 2012.

CHASSOT, A. I. Alfabetização científica: questões e desafios para a educação. Ijuí: Editora Unijuí, 2001. COPELLO, K. R., SANTOS, F. C., MUMBACH, S., MEURER, A. C. Uma atividade diferente em aulas de matemática na escola do campo. Atas do II Seminário Internacional de Educação do Campo e Fórum Regional do Centro e Sul do RS (SIFEDOC). Santa Maria (RS), 2014.

CREPALDE, R. S., AGUIAR JR, O. G. A formação de conceitos como ascensão do abstrato ao concreto: da energia pensada à energia vivida. Investigações em ensino de Ciências, v. 18, n. 02, p. 299-325, 2013a.

CREPALDE, R. S., AGUIAR JR, O. G. O desenvolvimento do conceito energia em um diálogo intercultural entre as ciências e as vivências de estudantes de licenciatura do campo. Atas do VIII Encontro Nacional de Pesquisa em Educação em Ciências (ENPEC). Campinas (SP), 2011.

CREPALDE, R. S., AGUIAR JR., O. G. Palavra própria e palavra alheia: análise de uma Questão Socialmente Controversa numa turma de Licenciatura do Campo. Atas do IX Encontro Nacional de Pesquisa em Educação em Ciências (ENPEC). Águas de Lindóia (SP), 2013b.

D’AMBROSIO, U. Etnomatemática, São Paulo: Editora Ática, 1987. 
D'AMBROSIO, U. Etnomatemática: Elo entre as tradições e a modernidade. Belo Horizonte: Autêntica, 2001.

DELIZOICOV, D. ANGOT'TI, A. J.; PERMANBUCO, M. M. Ensino de Ciências: fundamentos e métodos. São Paulo: Ed. Cortez, 2002.

DEMO, P. Educar pela pesquisa. Campinas: Autores Associados, 1998.

FERNANDES, B. M. Diretrizes de uma caminhada. ARROYO, M. G.; CALDART, R. S.; MOLINA, M. C. (org.) Por uma Educação do Campo. Petrópolis: Vozes, 2004.

FERNANDES, C. S., STUANI, G. M. A temática dos Agrotóxicos no Ensino de Ciências: as compreensões de estudantes da Licenciatura em Educação do Campo. Atas do IX Encontro Nacional de Pesquisa em Educação em Ciências (ENPEC). Águas de Lindóia (SP), 2013.

FERREIRA, D. F. O ensino de ciências no contexto de comunidades tradicionais na Ilha dos Marinheiros: uma análise sobre os saberes de mundo aplicados no ensino de ciências na educação de jovens e adultos. Atas do II Seminário Internacional de Educação do Campo e Fórum Regional do Centro e Sul do RS (SIFEDOC). Santa Maria (RS), 2014.

FOUCAULT, M. A ordem do discurso. São Paulo: Loyola, 2000.

FOUCAULT, Michel. Vigiar e punir: nascimento da prisão. Petrópolis: Vozes. 1987.

FREIRE, P. Pedagogia do Oprimido. São Paulo: Paz e Terra, 2005.

GONÇALVEZ, F. C., GARCEZ, E.S.C., ARAUJO, P.H.A., ALVES, L. K. T., SOARES, M. H. B., MESQUITA, N. A. S. Planejamento e desenvolvimento de uma disciplina optativa na escola campo: o estágio como espaço de construção de saberes. Atas do VIII Encontro Nacional de Pesquisa em Educação em Ciências (ENPEC). Campinas (SP), 2011.

LEITE, K. C., PAULA, P. P., FONTANIVE, É. F. Representações sociais na matemática: um estudo nas escolas do campo. Atas do II Seminário Internacional de Educação do Campo e Fórum Regional do Centro e Sul do RS (SIFEDOC). Santa Maria (RS), 2014.

LIMA, L. A., FREIXO, A. A. Dialogando saberes no campo: um estudo de caso em uma Escola Família Agrícola. Atas do VIII Encontro Nacional de Pesquisa em Educação em Ciências (ENPEC). Campinas (SP), 2011.

LOPES FILHO, F. D., BRITO, R. P., LEITE, M. A. O programa etnomatemática para o ensino da matemática no campo: uma reflexão sobre a educação matemática de jovens e adultos na Vila de Tamatateua, Bragança, Pará, Brasil. Atas do II Seminário Internacional de Educação do Campo e Fórum Regional do Centro e Sul do RS (SIFEDOC). Santa Maria (RS), 2014.

LOPES, T. M., ZANCUL, M. C. S. Concepções de meio ambiente no Projeto Político Pedagógico e nos Planos de Ensino de professores de uma escola do campo. Atas do IX Encontro Nacional de Pesquisa em Educação em Ciências (ENPEC). Águas de Lindóia (SP), 2013.

MENDES, I. A. O Estudo da Realidade como Eixo da Formação Matemática dos Professores de Comunidades Rurais. Bolema, v. 23, n. 36, p. 571-595, ago. 2012.

MIRANDA, C. T., JUNIOR SANTOS, G. PINHEIROS, N. A. M., SILVEIRA, R. M. C. F. Matemática e CTS: o ensino de medidas de áreas sob o enfoque da ciência tecnologia e sociedade em uma escola do campo. Atas do VIII Encontro Nacional de Pesquisa em Educação em Ciências (ENPEC). Campinas (SP), 2011.

MOLINA, M. C. Política de formação de educadores do campo no contexto da expansão do ensino superior. Revista Educação em Questão, Natal, v. 51, n. 37, p. 121-146, jan./abr. 2015.

MOLINA, M. C.; FREITAS, H. C. A. Avanços e desafios na construção da educação do campo. Em Aberto, Brasília, v. 24, n. 85, p. 17-31, abr/2011.

MUELLER, C. C., LINDNER, E. L. A construção do conhecimento em comunidades rurais e a recuperação dos saberes locais. Atas do IX Encontro Nacional de Pesquisa em Educação em Ciências (ENPEC). Águas de Lindóia (SP), 2013. 
PANIAGO, R. N., ROCHA, S. A., PANIAGO,J. N. A pesquisa como possibilidade de ressignificaçãodas práticas de ensino na escola no/do campo. Ensaio, v. 16, n. 01, p. 171-188, jan-abr 2014.

PAULA, H. F., CASTRO, M.E.C. Formulação de questões e mediação da leitura. Investigações em ensino de Ciências, v. 15, n. 03, p. 429-461, 2010.

PEREIRA, E. L. Metodologia do ensino de ciências em uma escola do campo em Barracão. Atas do II Seminário Internacional de Educação do Campo e Fórum Regional do Centro e Sul do RS (SIFEDOC). Santa Maria (RS), 2014.

PLENS, D., ADRIANO, J. Contribuições da escola paulo freire para a construção da educação do campo. Atas do II Seminário Internacional de Educação do Campo e Fórum Regional do Centro e Sul do RS (SIFEDOC). Santa Maria (RS), 2014.

ROBAINA, J. V., DIAS, L. F., PAZ, F. J. CUNHA, G. G. Vivenciando ciências na educação do campo: propostas interdisciplinares para a melhoria da qualidade do ensino em escolas rurais. Atas do II Seminário Internacional de Educação do Campo e Fórum Regional do Centro e Sul do RS (SIFEDOC). Santa Maria (RS), 2014.

SAUVÉ, L. Educação Ambiental e Desenvolvimento Sustentável: uma análise complexa. Revista de Educação Pública, v. 6, n. 10, p. 72-102, 1997.

SAUVÉ, L. Educação Ambiental: possibilidades e limitações. Educação e Pesquisa, São Paulo (SP), v. 31, n. 2, p. 317-322, maio/ago. 2005.

SILVA, A. F., QUEIROZ, J. G. O., SANTOS, M. C., BRICK, E. M. A produção leiteira em passos maia como tema gerador de um projeto comunitário. Atas do II Seminário Internacional de Educação do Campo e Fórum Regional do Centro e Sul do RS (SIFEDOC). Santa Maria (RS), 2014.

SILVA, C.R., FREITAS, D. Ecoletramento. O ensino de ciências na escola do campo. Atas do VIII Encontro Nacional de Pesquisa em Educação em Ciências (ENPEC). Campinas (SP), 2011.

SILVA, D. A., MULLER, F. S., DOMARESKA, A. A. Programa Institucional de Bolsas de Iniciação à Docência - PIBID matemática e a experiência de ensino-aprendizagem no colégio estadual indígena rio das cobras. Atas do II Seminário Internacional de Educação do Campo e Fórum Regional do Centro e Sul do RS (SIFEDOC). Santa Maria (RS), 2014.

SILVA, R. F. V. N., LIMA, I. M. S, LIMA, A. S. Atividades propostas por professores de matemática que trabalham em escolas do campo. Atas do II Seminário Internacional de Educação do Campo e Fórum Regional do Centro e Sul do RS (SIFEDOC). Santa Maria (RS), 2014.

SILVEIRA, D. I., LORECINI JÚNIOR, A., FAGUNDES, M. C. V. Educação Ambiental: comparando dados de uma escola urbana com uma escola do campo. Atas do IX Encontro Nacional de Pesquisa em Educação em Ciências (ENPEC). Águas de Lindóia (SP), 2013.

SOUZA, M. G. O diálogo freireano como estratégia de pesquisa no assentamento renascer. Atas do II Seminário Internacional de Educação do Campo e Fórum Regional do Centro e Sul do RS (SIFEDOC). Santa Maria (RS), 2014.

SPIELMANN, J. W., PACHECO, C. R. C. Os desafios e possibilidades do ensino da matemática na educação do campo: experiências de estágio. Atas do II Seminário Internacional de Educação do Campo e Fórum Regional do Centro e Sul do RS (SIFEDOC). Santa Maria (RS), 2014.

STRAGLIOTTO, M., DUARTE, C. G. As diferentes formas de operar matematicamente no mundo, desenvolvidas e utilizadas por agricultores do estado de Santa Catarina. Atas do II Seminário Internacional de Educação do Campo e Fórum Regional do Centro e Sul do RS (SIFEDOC). Santa Maria (RS), 2014.

TAFFAREL, C. Z.; SANTOS Jr. C. de L.; GAMA, C. N.; LIMA, J. F. de; SÁ, K. O. de; CARVALHO, M. S.; SILVEIRA, M. L. O.; PERIN, T. de F. Desafios da Educação do Campo na UFBA: proposições superadoras - o sistema complexos. In: MOLINA, M. C.; SÁ, L. M. (Orgs.) Licenciaturas em Educação do Campo: registros e reflexões a partir das experiências-piloto. Belo Horizonte: Autêntica, 2011. (Coleção Caminhos da Educação do Campo; 5). 
TAVARES, M. L., VALADARES, J. M., CREPALDE, R. S. Uma experiência de articulação entre conhecimentos de uma disciplina de biologia e outra de física do currículo de um curso de licenciatura para o campo com ênfase em ciências da vida e da natureza (CVN) de uma universidade federal brasileira. Atas do VIII Encontro Nacional de Pesquisa em Educação em Ciências (ENPEC). Campinas (SP), 2011.

Vigotski, L.S. A construção do pensamento e da linguagem. Trad. Paulo Bezerra. São Paulo: Martins Fontes, 2009.

WITTGENSTEIN, L. Investigações Filosóficas. Petrópolis: Vozes, 2004.

\section{NOTAS}

1 “[...] o surgimento da expressão "Educação do Campo" pode ser datado. Nasceu primeiro como Educação Básica do Campo no contexto de preparação da I Conferência Nacional por uma Educação Básica do Campo, realizada em Luziânia, Goiás, de 27 a 30 de julho 1998. Passou a ser chamada Educação do Campo a partir das discussões do Seminário Nacional realizado em Brasília de 26 a 29 de novembro 2002, decisão posteriormente reafirmada nos debates da II Conferência Nacional, realizada em julho de 2004.” (CALDART, 2012. p. 259-260).

${ }^{2}$ Universidade Federal de Minas Gerais (UFMG), Universidade de Brasília (UnB), Universidade Federal da Bahia (UFBA) e Universidade Federal de Sergipe (UFS).

${ }^{3}$ Molina (2015, p. 152) explica que "A matriz curricular proposta desenvolve uma estratégia multidisciplinar de trabalho docente, organizando os componentes curriculares a partir de quatro áreas do conhecimento: Artes, Literatura e Linguagens; Ciências Humanas e Sociais; Ciências da Natureza e Matemática e Ciências Agrárias".

${ }^{4}$ Em consonância com o Edital no 2 de 05/09/2012.

${ }^{5}$ É importante destacar que embora a revisão aqui apresentada não contemple capítulos de livros e periódicos classificados como B1 e B2, reconhece-se que eles apresentam contribuições significativas, em termos de quantidade e de qualidade, em relação à temática enfocada neste estudo. Contudo, consideramos que um número elevado de artigos dificultaria uma análise mais sistemática e detalhada, por isso, tais trabalhos serão foco de outros estudos.

${ }^{6}$ Os Três Momentos Pedagógicos (DELIZOICOV, ANGOTTI, PERNAMBUCO, 2002) buscam possibilidades de estabelecer uma dinâmica de atuação docente em sala de aula que esteja em sintonia com a perspectiva dialógico-problematizadora de Freire (2005). Esses momentos correspondem a: 1) Problematização Inicial, que consiste em identificar e problematizar as interpretações que os alunos têm sobre a situação significativa abordada; 2) Organização do Conhecimento, momento em que o professor seleciona quais conhecimentos científicos são pertinentes para dialogar com as questões apontadas pelos alunos e pelo professor; e 3) Aplicação do conhecimento, etapa em que o aluno, de posse do conhecimento científico, faz uso deste para compreender a situação que originou a problematização e estabelecer relações com outras questões que sejam pertinentes.

\section{Submetido em 31/10/2016 \\ Aprovado em 07/11/2017}

\section{Contato:}

Karine Raquiel Halmenschlager

Departamento de Metodologia de Ensino (MEN/CED)

Universidade Federal de Santa Catarina - Campus Universitário Trindade

CEP: 88040-900 - Florianópolis, SC - Brasil. 